This manuscript has been submitted for publication in THE LEADING EDGE (TLE). Please note that, despite having undergone peer-review, the manuscript has yet to be formally accepted for publication. Subsequent versions of this manuscript may have slightly different content. If accepted, the final version of this manuscript will be available via the 'Peer-reviewed Publication DOI' link on the right-hand side of this webpage. Please feel free to contact any of the authors; we welcome feedback. 


\title{
60 YEARS OF AIRBORNE AFMAG METHOD EVOLUTION
}

\author{
Alexander Prikhodko ${ }^{1 *}$, Petr Kuzmin ${ }^{2}$, Andrei Bagrianski ${ }^{1}$ \\ ${ }^{1}$ Expert Geophysics Limited, Canada \\ ${ }^{2}$ Magenta Geophysics Ltd., Canada \\ *Corresponding author e-mail: alexander@expertgeophysics.com
}

\begin{abstract}
Development and following commercial use of the airborne electromagnetic method based on natural fields in the audio-frequency band (AFMAG) started in late 50s of the last century. After several decades of the development downtime, limitations inherent to the method were resolved in 80 s by adapting the tensor analysis, remote reference noise bias removal techniques and computation of the tippers. The achievements were implemented in the ground acquisition system, and the "tipper" measurement principles employed in the following airborne system development in early 2000s (ZTEM). The latest development, MobileMT, the third generation airborne system from AFMAG family, offered for commercial surveys, overcomes the limitations of its predecessors.
\end{abstract}

\section{INTRODUCTION}

Attention to the airborne electromagnetic method based on natural fields is continued already for 60 years due to its main attractive potential - the achievement of significant depth of investigation without exploiting technically limited primary field controlled sources. The first commercially used system AFMAG developed in the middle of the last century (Ward, 1959) was limited by the electronics development level and the initial stage of theoretical background of the method principles. The development of theory and practice in 70s and 80s (Vozoff, 1972; Labson et al., 1985) triggered later developments in the airborne electromagnetics based on natural fields. In particular, the tipper type, magnetovariational airborne platform ZTEM became the next AFMAG generation for commercial surveys in 2000s. Limited ZTEM bandwidth, number of frequencies windows, absence of denoising data with remote reference station, "the lack of an intrinsic apparent- resistivity measurement, lack of ability to image layered geology" (Jansen and 
Cristall, 2017) have prompted to the next AFMAG representative development. MobileMT - is the latest development in the airborne natural fields electromagnetics (EM) in the audio and subaudio frequency range. The main achievements of the development include apparent conductivity output, three-component receiver system, ground remote referencing capability, expanded bandwidth and many frequency windows enough for representative selection in case of noise interference and weak natural signal in specific frequency ranges.

\section{AFMAG DEVELOPMENT BRIEF HISTORY}

The first period of theoretical development and practical usage of AFMAG, as an inductive electromagnetic method exploited audio frequency natural magnetic fields, was reflected in a series of publications in the period of 1958-1968 years (Ward et al., 1958, 1959, 1966, 1968). The airborne AFMAG commercially used in 1960s and early 1970s by McPhar Geophysics Limited (Thomson et. al., 2007). Technically, separation of the time-variance from the space-variance of the fields was the fundamental problem of the method. A comparator measuring technique became a solution for the initial AFMAG under the idea that "the time variations affect two detectors identically, yet space variations affect them differently" (Ward, 1966). Ward (1966) listed several advantages of the method. The most important among them are: depth of investigation exceeding any other airborne electromagnetic method (1); capability for deep structural mapping (2); advantage in exploration in rugged terrain in comparison with other airborne EM (3). At the same time, critical and inherent to AFMAG limitations (with only two frequencies, 150 and $510 \mathrm{~Hz}$ of data) were formulated which, most likely, slowed down the method usage and its further development. Apparently, those limitations mostly related to comparatively low electronic and computation levels of development.

Further magnetotelluric method theory and experimental techniques development (Vozoff, 1972; Labson et al., 1985) became the basis for the subsequent technical development of the method. In particular, Labson et al. (1985) resolved many of the method's critical limitations by adapting the tensor analysis and computation of the tipper, a coefficient which relates the vertical to the horizontal magnetic fields. Based on the development, the authors designed magnetic field sensors and built a digital acquisition and processing system for providing measurements of the audio- frequency tippers on the ground. In particular, the authors suggested using cross-spectral estimates of the tipper components $\mathrm{Tx}$ and $\mathrm{Ty}$, free of the auto-spectral noise component. This way 
implies measurements of the reference magnetic fields by sensors some distance away (often called as a base-station). This approach named as "the reference tipper method" has been realized later in the commercially exploited airborne system ZTEM (Morrison, Kuzmin, 2005). The system, measuring only vertical component (Lo, Zang, 2008; Legault, 2012), can be considered as a simplified representative of the AFMAG method family.

ZTEM, developed in 2005-2006, became the first commercial airborne 'AFMAG' system in more than 40 years after the initial AFMAG (Legault et al., 2013). ZTEM system is based on measuring of the vertical magnetic component of the induced signal which caused mostly by lateral resistivity variations in the subsurface geology. ZTEM outputs are the tipper components as the transfer function of a vertical magnetic field from airborne receiver to the horizontal magnetic components at a ground reference receiver (Lo, Zang, 2008). Tipper measurements (Hz/Hx or $\mathrm{Hz} / \mathrm{Hy}$ ) are dimensionless, can’t resolve layered geology and tipper responses are considerably diminished for compact 3D bodies in comparison with 2D geological strikes (Jansen and Cristall, 2017).

ZTEM system is limited by 5-6 frequencies of data in the $30-720 \mathrm{~Hz}$ or $25-600 \mathrm{~Hz}$ bandwidth (Fig.1), which is derived depending on signal strength (Lo et al., 2009). ZTEM data sampling is $2 \mathrm{kHz}$ using a 24 bit ADC (Lo and Zang, 2008). Since tilt of the flying coil is unstable during a survey, ZTEM uses attitude sensors to correct the source of the error (Morrison, Kuzmin, 2005). The quality of error correction is affected by unknown differences of horizontal components between the audio-magnetic field magnitudes in the base and flight points (Kuzmin et al., 2010).

Other airborne AFMAG prototypes (2001, 2002) developed in Geotech Ltd. basically played the role of transitional designs. AirMt system with three orthogonal receiver coils (Kaminski et al., 2010) announced being at an R\&D and not commercially available (Legault, 2012). Dicon/Q-Trac airborne EM system introduced in 1997 by Barringer Geosystems based on natural source AMT/MT as well was listed under the testing/R\&D status (Nabighian and Asten, 2002).

\section{MOBILEMT PLATFORM AS AN EVOLUTIONARY DEVELOPMENT}

MobileMT system was developed by Expert Geophysics Limited in order to continue the evolution of the airborne electromagnetic natural fields technology and introduced in 2018 (Sattel, 
2019), 12 years after ZTEM introduction and 60 years after the first AFMAG. Jansen and Cristall (2017) predicted one year before that: "Improved three-component receiver systems will most likely be developed, which if oriented would provide vector data, or if not would provide a totalfield measurement...”. Sattel (2019) presented a simplified tensor expression without $\mathrm{Hz}$ involvement based on same mathematics as the ground MT soundings. In fact, the Mobile MT utilizes three orthogonal magnetic field components in the air, to get total field value, while a ground station consists of two horizontal electric filed components and measures variations of the electric field. The ratio of magnetic to electric field magnitudes in both in-phase and out-of-phase components provides analytic parameters in selected bands of frequencies. Advanced noise processing of both electronic and signal processing levels ensures non-biased and high-quality data even in case of low natural EM fields. It is the admittance-type data and ultimate output data is in $\mathrm{mS} / \mathrm{m}$ units for each extracted frequency. Since total field is calculated from the three components, no attitude correction is required.

MobileMT employs an electric ground station, measuring reference and signal electric field in two perpendicular directions with four pair of electrodes. Signal-to-noise ratio for the electrical field measurements is considered much higher than the signal-to-noise ratio for the magnetic field (Labson et al. 1985) what is one of MobileMT advantages. Each electrical component on the base station is registered independently from two grounded lines - signal and reference - which is utilized to eliminate the data bias distortions, as suggested by Labson et al.(1985).

MobileMT's electromagnetic data is digitized and recorded at $73,728 \mathrm{~Hz}$ in the measurement frequency range $30 \mathrm{~Hz}-20,000 \mathrm{~Hz}$ (Fig.1). Frequency windows width and the windows number in the range are customizable depending on signal strength and frequency of any source of industrial noise.

The table below includes main technical specifications of the commercially used airborne electromagnetic systems from the AFMAG family. 
Table 1 Technical specifications of the commercially used airborne AFMAG systems (1958-2018)

\begin{tabular}{|c|c|c|c|}
\hline characteristic & AFMAG (1958) & ZTEM (2006) & MobileMT (2018) \\
\hline Detector type & $\begin{array}{l}2 \text { inductive coils in the air } \\
\text { at } 45^{\circ} \text { to the horizontal } \\
\text { and to each other in the } \\
\text { direction of flight. The } \\
\text { components are } \\
\text { compared electronically } \\
(\mathrm{H} \text {-field })^{1} \text {. }\end{array}$ & $\begin{array}{l}1 \text { vertical field inductive } \\
\text { coil in the air ( } \mathrm{H} \text {-field); } \\
2 \text { horizontal field } \\
\text { inductive coils on the } \\
\text { ground ( } \mathrm{H} \text {-field). }\end{array}$ & $\begin{array}{l}3 \text { orthogonal inductive } \\
\text { coils in the air (H-field); } \\
2 \text { pairs perpendicular } \\
\text { grounded electric lines (E- } \\
\text { field). }\end{array}$ \\
\hline Output data & $\begin{array}{l}\text { Tilt component of the } \\
\text { magnetic field along the } \\
\text { line direction. Deflections } \\
\text { are proportional to the tilt } \\
\text { of the plane of } \\
\text { polarization }{ }^{1} \text {. }\end{array}$ & $\begin{array}{l}\text { Tipper data. Sensitivity } \\
\text { "to current density } \\
\text { variations caused by } \\
\text { conductivity contrasts, } \\
\text { but not to the absolute } \\
\text { conductivities } \\
\text { themselves" }{ }^{2}\end{array}$ & $\begin{array}{l}\text { Admittance data } \\
\text { (apparent conductivity) }\end{array}$ \\
\hline $\begin{array}{l}\text { frequency bands } \\
(\mathrm{Hz})\end{array}$ & Typical $150 ; 510^{1}$ & $\begin{array}{l}32,45,90,180,360 \\
720^{3}\end{array}$ & $\begin{array}{l}20 \text { channels or } 30 \\
\text { channels with } 2 \text { different } \\
\text { options frequency } \\
\text { windows widths } \\
\text { distributed in } 30-20,000 \\
\text { Hz range }\end{array}$ \\
\hline $\begin{array}{l}\text { Data recording } \\
\text { sampling }(\mathrm{Hz})\end{array}$ & No digital recording & 2000 & 73728 \\
\hline $\begin{array}{l}\text { Bird tilting motion } \\
\text { compensation }\end{array}$ & Yes & Yes & Not required \\
\hline Signal bias problem & Yes & Yes & No \\
\hline $\begin{array}{l}\text { Sensitivity to } \\
\text { geoelectrical } \\
\text { boundaries } \\
\text { directions }\end{array}$ & $\begin{array}{l}\text { It is difficult or impossible } \\
\text { to recover conductors } \\
\text { with parallel axes to the } \\
\text { direction of the inducing } \\
\text { field }^{1}\end{array}$ & $\begin{array}{l}\text { lack of ability to image } \\
\text { layered geology }{ }^{2}\end{array}$ & $\begin{array}{l}\text { Sensitive to geoelectrical } \\
\text { boundaries of any } \\
\text { direction }\end{array}$ \\
\hline
\end{tabular}

1-(Ward et.al., 1966); 2- (Jansen, Cristall, 2017); 3-(Legault et. al. 2009) 


\section{MOBILEMT DATA PROCESSING PRINCIPLE}

The MobileMT data processing goal is determining a magnetotelluric admittance tensor response from synchronized and jointed time series data ExEyHxHyHz (Bagrianski et al., 2019). The Fast Fourier Technique (FFT) is applied to the recordings for converting the time-domain data to frequency domain. The next step is calculation the matrixes of the relations between the electric and magnetic signals (six admittances) on the different time bases and in different frequency bands.

The admittances $(\boldsymbol{Y})$ are represented as the electric field horizontal vectors projection into the space of the magnetic field three components. Generalizing the Weiss-Parkinson relationship (Berdichevsky and Zhdanov, 1984), such as that measured three orthogonal magnetic field components $(\boldsymbol{H} \mathrm{xyz})$ are linearly related to the horizontal electric fields measured on the ground (Exy, reference), with adoption it to the admittances domain $(\boldsymbol{Y})$ :

$$
\left[\begin{array}{l}
H x \\
H y \\
H z
\end{array}\right]=\left[\begin{array}{ll}
Y x x & Y x y \\
Y y x & Y y y \\
Y z x & Y z y
\end{array}\right]\left[\begin{array}{l}
E x \\
E y
\end{array}\right]
$$

The complex data spectrums (field examples in Figure 2) is expressed in apparent conductivity $(\sigma)$, as final output MobileMT data for each frequency:

$$
\sigma=\mu \omega\left|Y^{2}\right|
$$

where $\boldsymbol{Y}$ is the determinant of the corresponded matrix in (1); $\boldsymbol{Y}^{2}=\mathrm{im}\left(\boldsymbol{Y}^{2}\right) / \mathrm{re}\left(\boldsymbol{Y}^{2}\right) ; \boldsymbol{\mu}$ is the magnetic permeability of free air and $\boldsymbol{\omega}$ is the angular frequency.

Solutions of the equations (1) are obtained by averaging over a number of closely spaced frequencies. An example of frequency windows used for harmonics averaging MobileMT data shown in Picture 1.

\section{MOBILEMT FIELD TEST DATA EXAMPLES}

MobileMT data acquired across the Broken Evil VMS-gold prospect in the Abitibi Greenstone Belt (Northern Ontario) on February, 2018, and described by Sattel et. al (2019), presented in Fig.3B along a line together with historical time-domain dB/dt data (Fig.3A). Inversion of the MobileMT data into the resistivity-depth section presented in Fig.3C. 
Data from the different airborne EM technologies, time-domain and MobileMT, are responding to the same features of the geoelectrical environment - conductive overburden, vertical highly conductive structures and the shallow discrete conductor.

The next example is from the Shea Creek uranium deposit area (Fig.4). This is an unconformitystyle mineralization in the western part of the Athabasca Basin. In this part of the basin, the unconformity (contact between the early-proterozoic basement rocks and overlying midproterozoic sandstones) is nearly $700 \mathrm{~m}$ deep. As the example shows, the data from MobileMT system (flown in August 2018) is responding not only to highly conductive material at the unconformity line, $700 \mathrm{~m}$ depth and below, but shows an indication of an alteration halo within the overlying sandstone.

Inversions presented in the article were produced using the software package for MobileMT data nonlinear least-squares iterative inversion developed by Nikolay Golubev in 2019. The inversion algorithm is based on the conjugate gradient method with the adaptive regularization (Zhdanov, 2002).

The MobileMT two main field components are presented in Figure 5.

\section{CONCLUSION}

The mining sector's interest in deep and comparatively fast exploration over large areas is the main motivation factor of airborne electromagnetic methods development, specifically methods based on the passive principle, called AFMAG. During the last 60 years, since the method was formulated and corresponded system introduced, the method theory, electronics and signal processing have been developed enormously. This led to the successful development of the ZTEM system, commercially exploited during almost 15 years. The latest development in the airborne AFMAG method family is MobileMT system, which going further expanding bandwidth, increasing frequency resolution, using three component receiver, becoming sensitive to absolute conductivity and to any direction of geoelectric boundaries.

Technically, MobileMT system is defined by the next: 
- passive measurement of the earth's natural magnetic $(\boldsymbol{H})$ field variations in the air with simultaneous measurement of natural electric field $(\boldsymbol{E})$ on the surface;

- Measure changes in $\boldsymbol{H}$ with time and space and changes in $\boldsymbol{E}$ with time;

- Frequency range $30 \mathrm{~Hz}$ to $20,000 \mathrm{~Hz}$ divided by 20 or 30 windows.

The combined ( $\boldsymbol{E}$ and $\boldsymbol{H}$ ) MobileMT system measures combination of tensor and scalar (rotational invariant) components as the transfer function (in-phase and quadrature) of a total magnetic field, through the three orthogonal directions measurements of an airborne receiver, to the two orthogonal horizontal directions of electric field measured at a ground base location.

\section{REFERENCES}

Bagrianski, A., Kuzmin, P., Prikhodko, A., 2019, AFMAG Evolution - expanding limits: Extended Abstracts - 16th SAGA Biennial Conference \& Exhibition.

Berdichevsky, M.N., and Zhdanov, M.S., 1984, Advanced theory of deep geomagnetic sounding: Elseiver

Jansen, J.C., Cristall, J.A., 2017, Mineral Exploration Using Natural EM Fields: In "Proceedings of Exploration 17: Sixth Decennial International Conference on Mineral Exploration" edited by V. Tschirhart and M.D. Thomas, 2017, 349-377.

Kaminski, V. F., Kuzmin, P., and Legault, J.M., 2010, AirMt - Passive airborne EM system: Presented at the 3rd CMOS-CGU Congress.

Kuzmin, P. V., Borel G., Morrison, E. B. and Dodds, D. J., 2010, Geophysical prospecting using rotationally invariant parameters of natural electromagnetic fields: U.S. Patent No. 8,289,023.

Labson, V.F., Becker, A., Morrison, H.F., Conti, U., 1985, Geophysical exploration with audiofrequency natural magnetic fields: Geophysics, Vol.50, No 4, 656-664. 
Legault, J.M., Kumar, H., Milicevic, B., Hulbert L., 2009, ZTEM airborne tipper AFMAG test survey over a magmatic copper-nickel target at Axis Lake in northern Saskatchewan: SGS Open House, 2-Dec-2009, Saskatoon, SK. From: https://pubsaskdev.blob.core.windows.net/pubsaskprod/95137/95137-Legault Open House 2009.pdf

Legault, J.M., 2012, Ten years of passive airborne AFMAG EM development for mineral exploration: SEG Technical Program Expanded Abstracts.

Legault, J.M., Prikhodko A., Tishin P., Dodds J., 2013, New airborne EM systems development for 2013: Presented at CAMESE Innovations Forum.

Lo, B., and Zang, M., 2008, Numerical modeling of Z-TEM (airborne AFMAG) responses to guide exploration strategies: 78th Annual International Meeting, SEG, Expanded Abstracts, 1098-1101.

Lo, B., Legault J. M., Kuzmin, P., and Combrinck M., 2009, Z-TEM (Airborne AFMAG) tests over unconformity uranium deposits: 20th International Geophysical Conference \& Exhibition, ASEG, Extended Abstracts, 1-6.

Morrison E.B., Kuzmin, P. V., 2005, System, method and computer product geological surveying utilizing natural electromagnetic fields, U.S. Patent No. 6,876,202.

Nabighian, M.N., and Asten, M.W., 2002, Metalliferous mining geophysics - State of the art in the last decade of the 20th century and the beginning of the new millennium: Geophysics, VOL. 67, NO. 3, 964-978.

Sattel D., Witherly K., Kaminski V., 2019, A brief analysis of MobileMT data: SEG International Exposition and 89 Annual Meeting.

Thomson, S., Fountain, D., Watts, T., 2007, Airborne Geophysics - Evolution and Revolution: In "Proceedings of Exploration 07: Fifth Decennial International Conference on Mineral Exploration" edited by B. Milkereit, 19-37.

Zhdanov M.S., 2002, Geophysical inverse theory and regularization problems: Elsevier. Methods in Geochemistry and Geophysics, 36. 
Vozoff, K., 1972, The magnetotelluric method in the exploration of sedimentary basins: Geophysics, 37, 98-141.

Ward, S.H., 1959, AFMAG - Airborne and ground: Geophysics, Vol. 24, No.4, 761-789.

Ward, S. H., Cartier, W.O., Harvey, H.A., McLaughlin, G.H., and Robinson, W.A., 1958, Prospecting by use of natural alternating magnetic fields of audio and sub-audio frequencies:

Trans., Canadian Mining and Metall. Bull., v.61, 261-268.

Ward, S.H., O’Donnell J., Rivera R., Ware G.H., Fraser D.C., 1966, AFMAG - applications and limitations: Geophysics, Vol.31, 576-605.

Ward, S.H., O’Brien, D.P., Parry, J.R., and McKnight, B.K., 1968, AFMAG - Interpretation: Geophysics, Vol.33, NO.4, 621-644. 


\section{LIST OF FIGURES}

Figure 1. MobileMT and ZTEM recorded frequency windows

Figure 2 - Airborne magnetic X-coil spectrum up to $20,000 \mathrm{~Hz}$ range (top) with the corresponded electric X-line spectrum (bottom)

Figure 3. MobileMT apparent conductivity data (B) and their inversion (C) in comparison with time-domain $\mathrm{dB} / \mathrm{dt}$ data (A) (line L7520).

Figure 4. MobileMT apparent conductivity data profiles and their inversion resistivity section along a line over Shear Creek deposit

Figure 5. MobileMT magnetic sensor in the air (left) and the acquisition system of the E-field base station (right). 
Fig.1

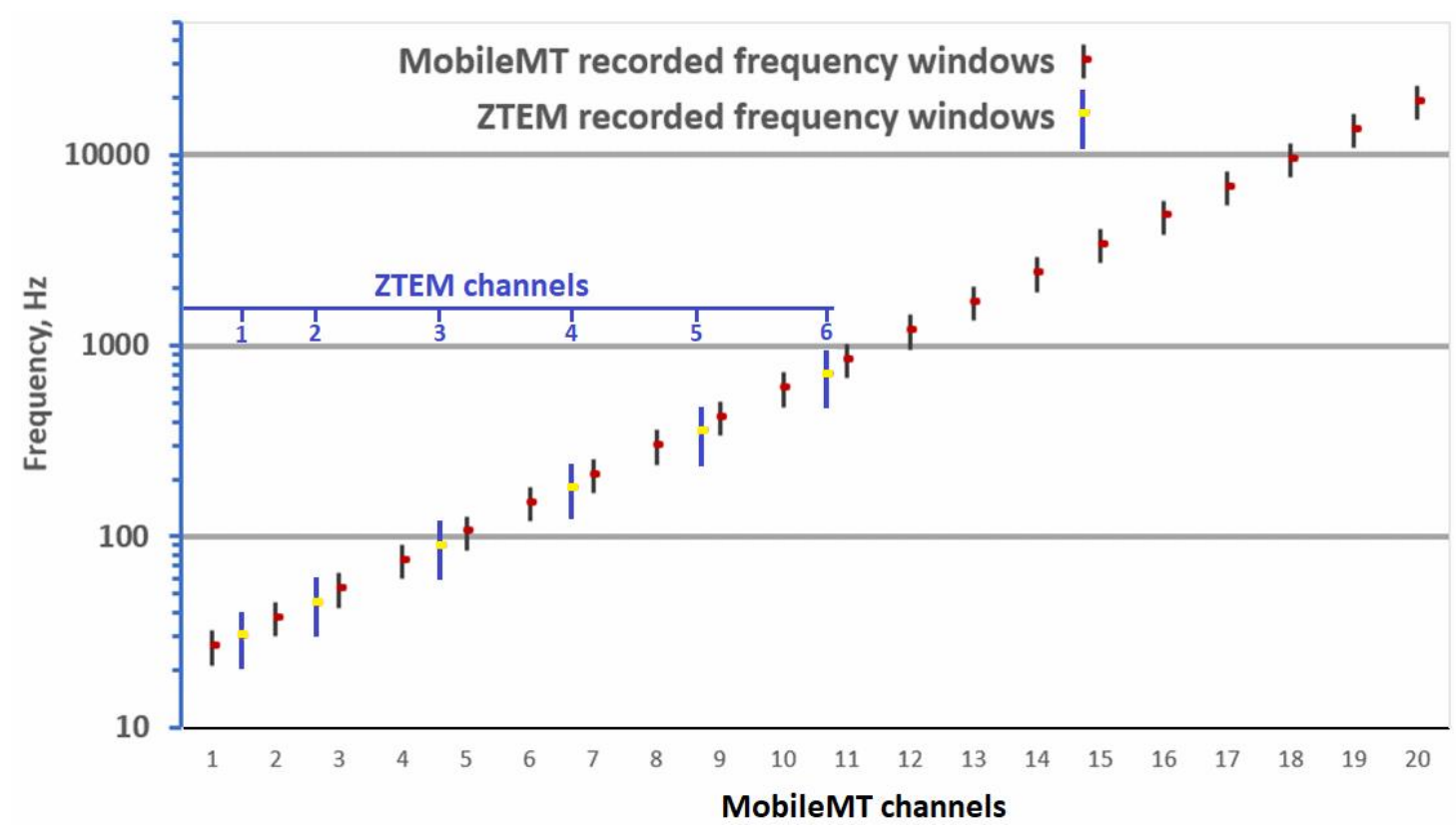

Fig.2
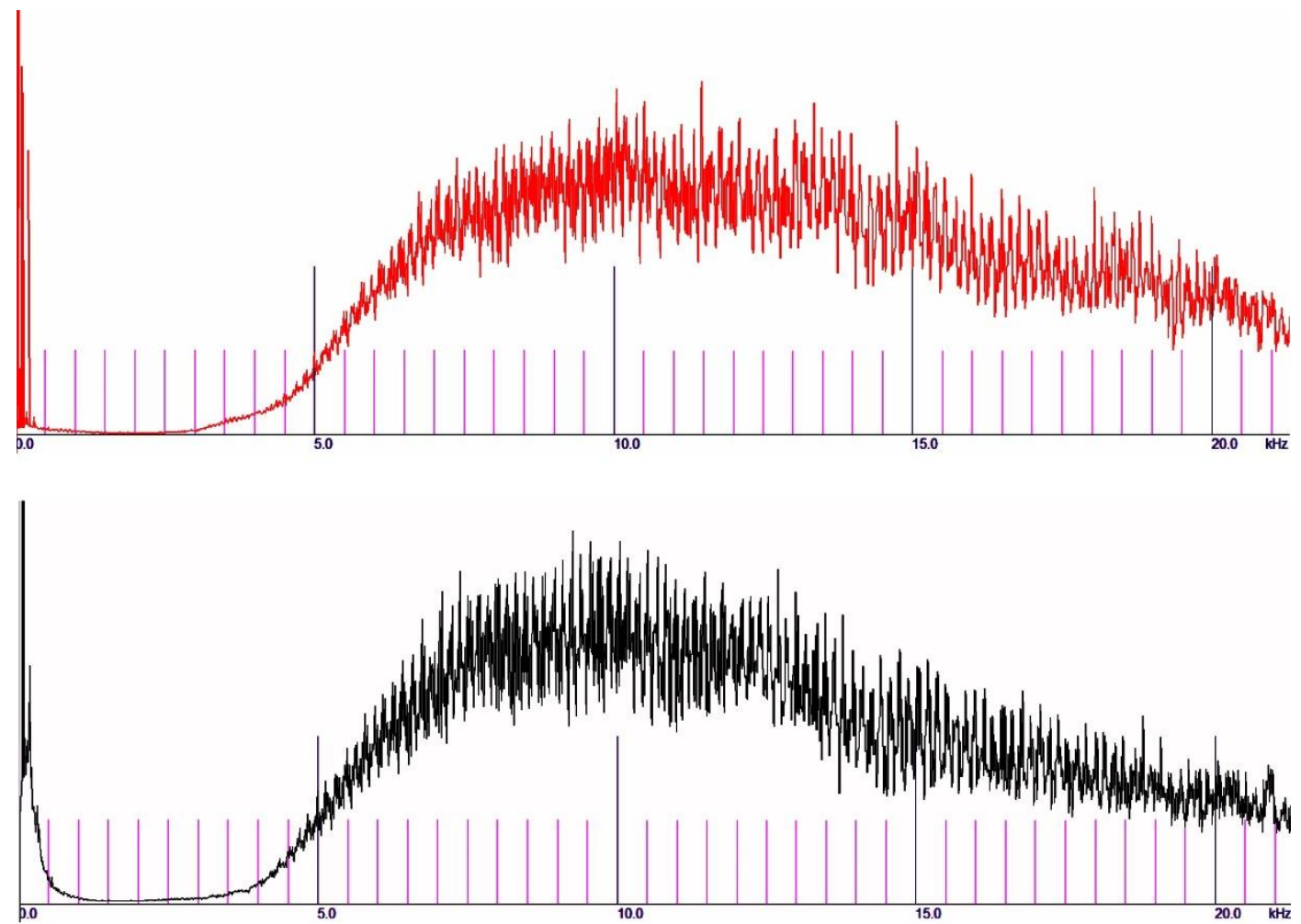
Fig.3

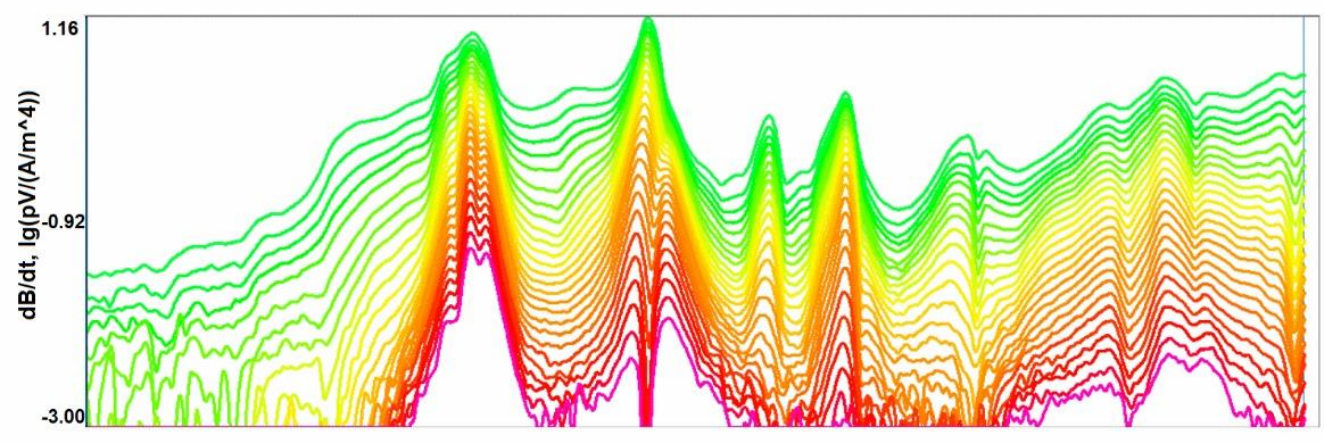

A
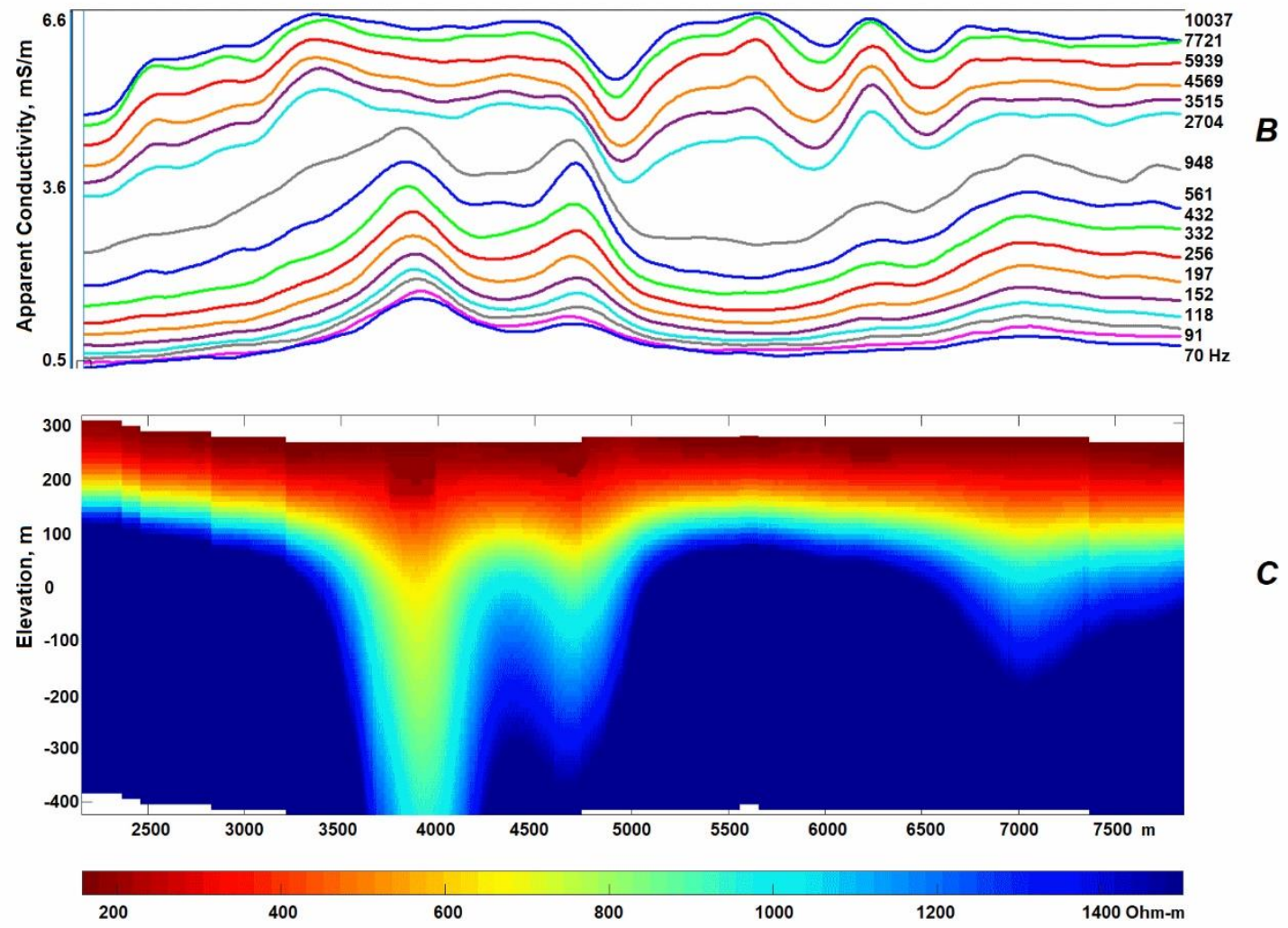

C 
Fig.4

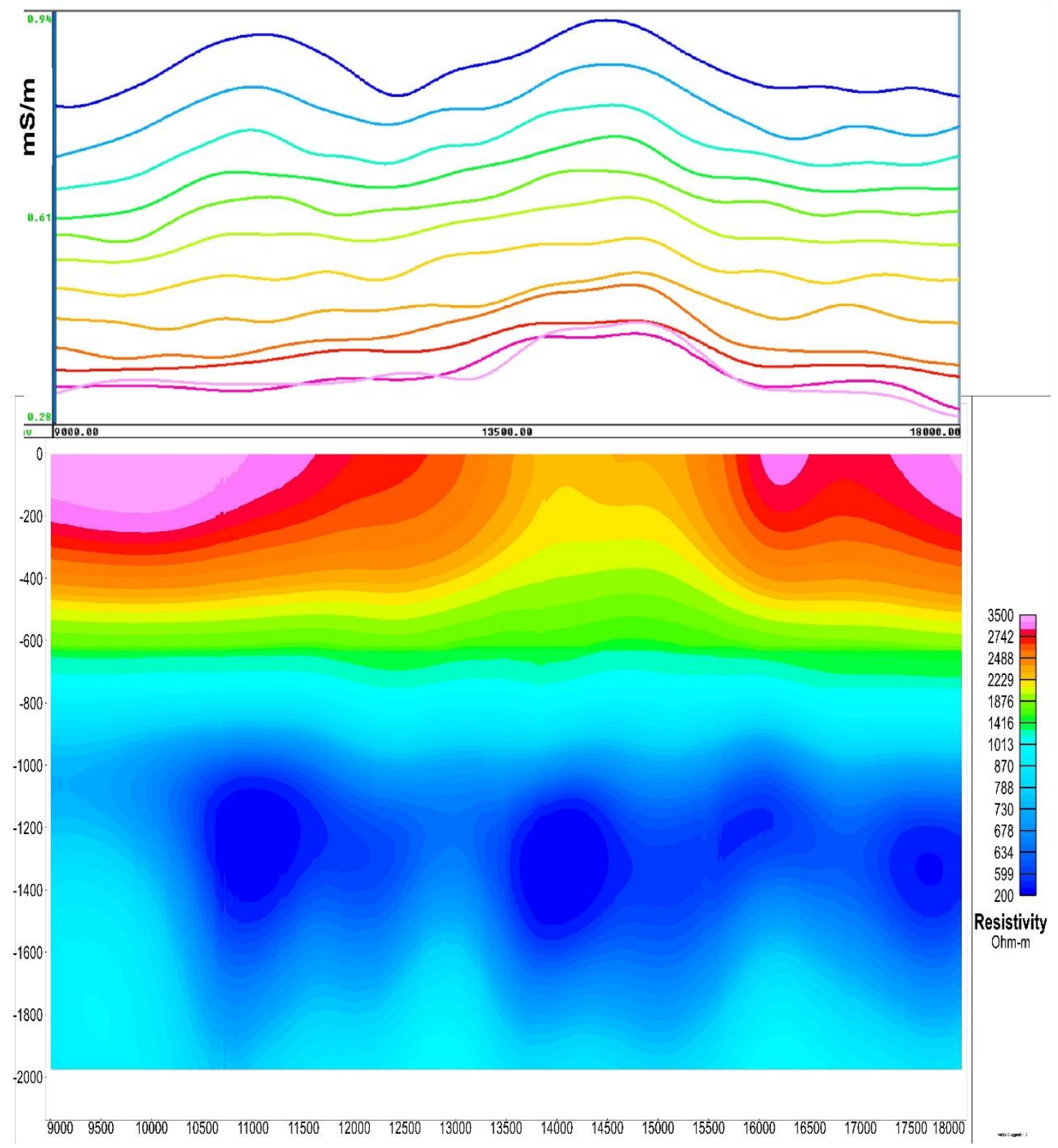


Fig.5

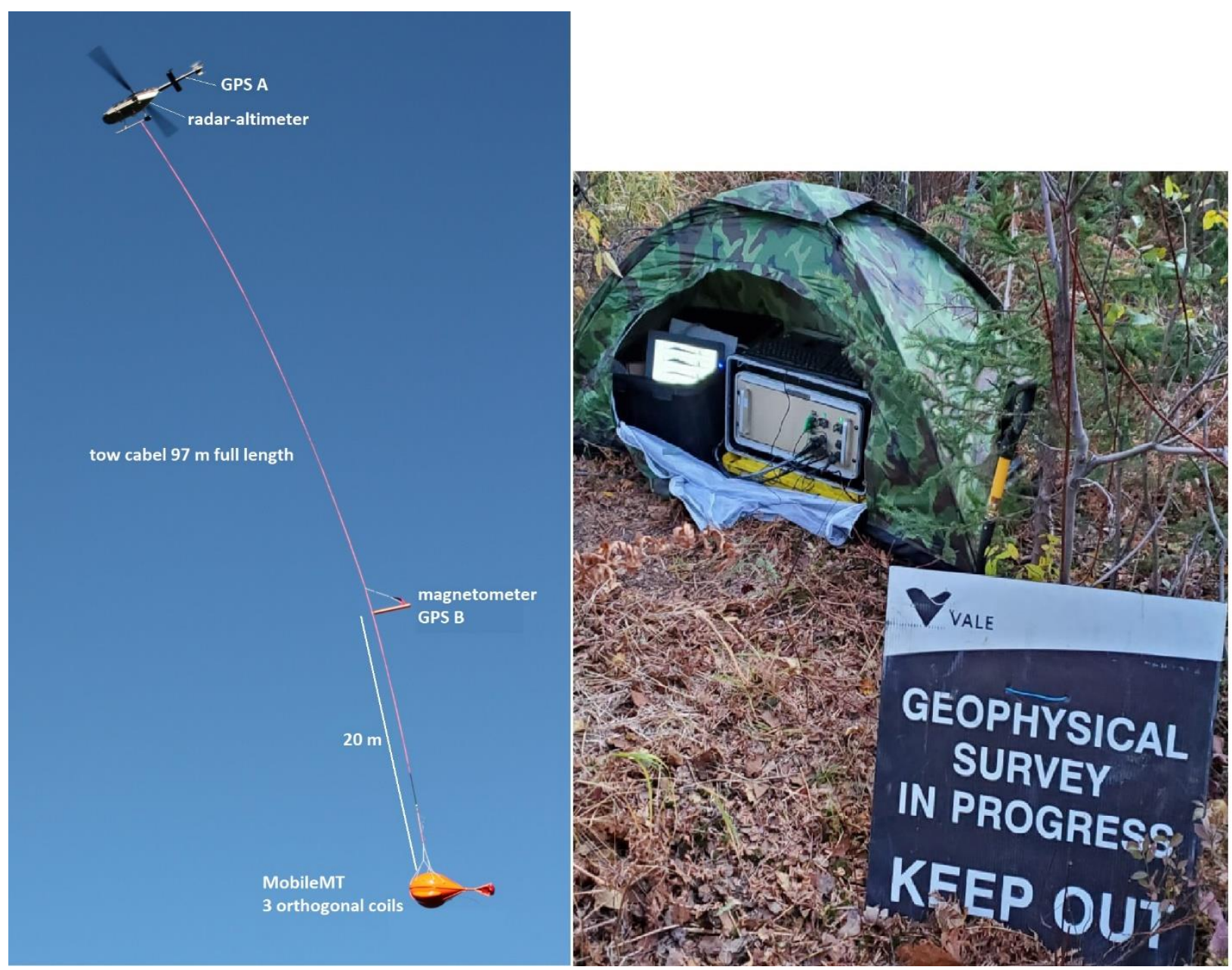

